ARTICLE

\title{
Accelerated discovery of superoxide-dismutase nanozymes via high-throughput computational screening
}

\author{
Zhenzhen Wang ${ }^{1,5}$, Jiangjiexing Wu (10) ${ }^{2,5}$, Jia-Jia Zheng ${ }^{1}$, Xiaomei Shen ${ }^{3}$, Liang Yan (i) ${ }^{4}$, Hui Wei (i) ${ }^{2}$, \\ Xingfa Gao (1) ${ }^{1 \times} \&$ Yuliang Zhao (1) ${ }^{4}$
}

The activity of nanomaterials (NMs) in catalytically scavenging superoxide anions mimics that of superoxide dismutase (SOD). Although dozens of NMs have been demonstrated to possess such activity, the underlying principles are unclear, hindering the discovery of NMs as the novel SOD mimics. In this work, we use density functional theory calculations to study the thermodynamics and kinetics of the catalytic processes, and we develop two principles, namely, an energy level principle and an adsorption energy principle, for the activity. The first principle quantitatively describes the role of the intermediate frontier molecular orbital in transferring electrons for catalysis. The second one quantitatively describes the competition between the desired catalytic reaction and undesired side reactions. The ability of the principles to predict the SOD-like activities of metal-organic frameworks were verified by experiments. Both principles can be easily implemented in computer programs to computationally screen NMs with the intrinsic SOD-like activity.

\footnotetext{
${ }^{1}$ Laboratory of Theoretical and Computational Nanoscience, National Center for Nanoscience and Technology of China, Beijing 100190, China. ${ }^{2}$ Department of Biomedical Engineering, College of Engineering and Applied Sciences, Nanjing National Laboratory of Microstructures, Jiangsu Key Laboratory of Artificial Functional Materials, Chemistry and Biomedicine Innovation Center (ChemBIC), Nanjing University, Nanjing, Jiangsu 210023, China. ${ }^{3}$ Key Laboratory of Functional Small Organic Molecule, College of Chemistry and Chemical Engineering, Jiangxi Normal University, Nanchang 330022, China. ${ }^{4}$ CAS Key Laboratory for Biomedical Effects of Nanomaterials and Nanosafety, Institute of High Energy Physics and National Center for Nanoscience and Technology, Chinese Academy of Sciences, Beijing 100049, P. R. China. ${ }^{5}$ These authors contributed equally: Zhenzhen Wang and Jiangjiexing Wu.

凶email: gaoxf@nanoctr.cn
} 
T he principles governing the activity of nanomaterials $(\mathrm{NMs})$ in the catalytically scavenging superoxide anion $\left(\mathrm{O}_{2}{ }^{-}\right)$underlie many biological effects of the materials, which are of great importance in both basic chemistry and therapeutic applications of the materials. $\mathrm{O}_{2}{ }^{--}$is an unavoidable byproduct of oxygen metabolism. An excess amount of $\mathrm{O}_{2} \cdot-$ triggers many severe diseases, such as heart disease, cardiovascular disease, cancer, diabetes, Alzheimer's disease, and Parkinson's disease ${ }^{1}$. To protect cells from $\mathrm{O}_{2}{ }^{\cdot-}$, biosystems have evolved a specific family of metalloenzyme called superoxide dismutases (SOD), which catalyze the dismutation of $\mathrm{O}_{2}{ }^{--}$to form biologically less harmful species, hydrogen peroxide $\left(\mathrm{H}_{2} \mathrm{O}_{2}\right)$ and $\mathrm{O}_{2}$ (Fig. 1a). Intriguingly, recent studies have demonstrated that some inorganic NMs possess the activity of scavenging $\mathrm{O}_{2}{ }^{\bullet-}$, which mimics SOD (Table 1). Compared to SOD, NMs are usually more stable and less expensive. Moreover, such enzymelike NMs (collectively called nanozymes) ${ }^{2-5}$ can simultaneously possess unique electronic and magnetic properties, which are not exhibited by SOD. Therefore, NMs with SOD-like catalytic activity has shown the potential to develop novel therapeutic strategies $^{5}$ in the area of radiation protection ${ }^{6}$ and the treatment of diseases such as vascular calcification ${ }^{7}$, immunodeficiencies ${ }^{8}$, and neurodegenerative diseases ${ }^{8}$.

However, the activities of these NMs in catalytically scavenging $\mathrm{O}_{2}{ }^{--}$are much weaker than those of SODs, hindering their widespread applications ${ }^{30}$. Lacking a general prediction theory, the rational design of NMs with sufficiently high activities along with other desired properties is particularly challenging. Dugan and coworkers suggested a two-step mechanism for water-soluble $\mathrm{C}_{60}$ fullerene catalytically scavenging $\mathrm{O}_{2}{ }^{-}$. The catalyst is first reduced by accepting an electron from $\mathrm{O}_{2}{ }^{--}$, followed by transferring the electron to another $\mathrm{O}_{2}{ }^{--}$; these two steps generate $\mathrm{O}_{2}$ and $\mathrm{H}_{2} \mathrm{O}_{2}$, respectively, in the presence of protons in the solution ${ }^{14}$. This mechanism has been verified by later studies on the SOD-like properties of other $\mathrm{C}_{60}$ derivatives ${ }^{9,31}, \mathrm{sp}^{2}$-carbon nanoparticles ${ }^{10,12,13}$, and perylene diimide ${ }^{11}$. Self and coworkers experimentally demonstrated that the SOD-like activity of nanoceria increases with the ratio of $\mathrm{Ce}^{3+}$ to $\mathrm{Ce}^{4+}$ in the material ${ }^{26}$. Using density functional theory (DFT) calculations, we computationally studied the rearrangements of $\mathrm{HO}_{2}{ }^{\bullet}$ radicals on the surfaces of nanoceria ${ }^{32}$ and noble metals ${ }^{33}$ in the gas phase, which suggested that the catalyst surfaces influence the catalytic activity by tuning the kinetic stability of the intermediate structures involved in the rearrangements ${ }^{32,33}$. Although these results have provided insights into the catalytic mechanisms and have revealed structure-activity relationships for some specific types of NMs, the general principles determining the activity are still elusive. On the other hand, previous studies have established a powerful principle, which is shown in Fig. 1b, for the activity of $\mathrm{SOD}^{34}$.
In this work, by learning from the principle of SOD and considering the differences between the NMs and SOD, we develop and verify a new energy level principle and adsorption energy principle for the SOD-like activity of NMs on the basis of their electronic band structures and surface adsorption energies, respectively. The energy level principle reveals the critical role of the intermediate frontier molecular orbital (iFMO), which is defined as the FMO of the NM with energy located in between $\varphi_{1}$ and $\varphi_{2}$, where $\varphi_{1}$ and $\varphi_{2}$ are the potentials of the half-reactions of $\mathrm{O}_{2}{ }^{\cdot-}$ dismutation, in transferring electrons for catalysis. The adsorption energy principle quantitatively describes the competition between the target catalytic reaction and possible side reactions for $\mathrm{O}_{2}{ }^{--}$on the catalysts. Therefore, the combination of both principles provides not only systematic and in-depth insight into the mechanisms of the SOD-like properties of NMs but also a general guide for the computational design and screening of SOD-like NMs.

\section{Results and discussion}

Energy level principle. We first developed a theoretical model to predict the activity of NMs catalyzing the dismutation of $\mathrm{O}_{2}{ }^{--}$. In nature, $\mathrm{SOD}$ is the enzyme that specifically catalyzes this reaction, and previous studies have achieved a thermodynamics-based model (Fig. 1b) ${ }^{34}$. According to this model, the reduction potential order $\varphi_{1}<\varphi_{\mathrm{SOD}}<\varphi_{2}$ is the sufficient and necessary condition for the activity of SOD. This condition ensures that both half-reactions of the dismutation are thermodynamically spontaneous and that the maximized activity is reached when $\varphi_{\mathrm{SOD}}=\left(\varphi_{1}+\varphi_{2}\right) / 2^{34}$. Because all reaction steps involved in SOD catalysis have low energy barriers ${ }^{34}$ and the catalyzes are under

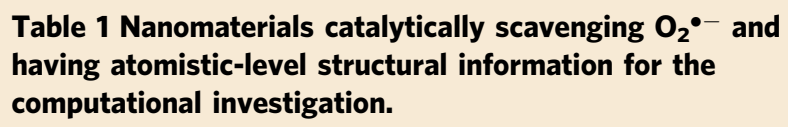

Fig. 1 Metalloenzyme catalytically scavenging $\mathbf{O}_{\mathbf{2}}^{\bullet-}$ - a The superoxide dismutase (SOD) that scavenges $\mathrm{O}_{2} \bullet-$ by catalyzing its dismutation reaction. b The reduction potential model predicting the catalytic activity of SOD. In $\mathbf{b}, \varphi_{1}$ and $\varphi_{2}$ are the reduction potentials of $\mathrm{O}_{2} / \mathrm{O}_{2}{ }^{-}$and $\mathrm{O}_{2}{ }^{-}, \mathrm{H}^{+} / \mathrm{H}_{2} \mathrm{O}_{2}$, respectively, and their values at $\mathrm{pH}=7$ are given in the parentheses. 
thermodynamic control, such a purely thermodynamics-based theoretical principle of SOD has stood the test of time ${ }^{34}$.

To develop a prediction model for NMs by learning from SOD, the following two differences between the NM and SOD must be considered. First, the electron energy levels responsible for electron transfer in catalysis are different. In SODs, the level is $\varphi_{\text {SOD }}$, i.e., the potential of $\mathrm{M}^{\mathrm{n}+1} \mathrm{SOD} / \mathrm{M}^{\mathrm{n}} \mathrm{SOD}$. In contrast, those of NMs are FMOs, which include the conduction band minimum $(\mathrm{CBM})$, valence band maximum (VBM), or mid-gap impurity level (MGIL). For bandgap NMs, the MGILs are associated with structural imperfections; for metal NMs, the MGILs are Fermi energy levels $\left(E_{\mathrm{F}}\right)$. Second, the possibilities of side reactions in the two cases are different. Because of its protein scaffolds, SOD catalyzes the dismutation of $\mathrm{O}_{2}{ }^{\bullet-}$ with high specificity. By contrast, side reactions may compete with the target catalytic reaction occurring on the NMs. These two differences suggest the necessity of developing new principles for the SOD-like activity of NMs.

Because FMOs are responsible for electron transfer in the case of NMs, we hereby adjust $\varphi_{\text {SOD }}$ in the model of SODs to the FMO energy $\left(E_{\mathrm{FMO}}\right)$ to fit with the NMs. A similar idea of using FMO energies as activity descriptors has been proposed for the oxidative dehydrogenation reactions catalyzed by $\mathrm{CeO}_{2}$-based catalysts ${ }^{35,36}$. Therefore, we obtain the energy level principle for NMs (Fig. 2a). According to this principle, we propose Eq. (1)

$$
\varphi_{1}<E_{\mathrm{FMO}}<\varphi_{2}
$$

to be the first criterion for screening $\mathrm{NMs}$ as $\mathrm{O}_{2}{ }^{--}$scavenging catalysts. Thereafter, we will denote the FMO satisfying Eq. (1) as iFMO. Similar to the case of SOD, when $E_{\mathrm{iFMO}}=\left(\varphi_{1}+\varphi_{2}\right) / 2$, the maximized catalytic efficiency of the NM will be anticipated when the other factors influencing the activity are the same. With this principle, it is easy to predict whether a NM is a potential SOD mimic. Figure $2 \mathrm{~b}$ illustrates XI types of electronic band structures of NMs: I - VIII are characteristics of bandgap NMs, and IX - XI are those of metal NMs. Among them, I, II, IV, V, and IX have a VBM, a CBM, an occupied MGIL (OMGIL), an unoccupied MGIL (UMGIL), and an $E_{\mathrm{F}}$ in the range $\left(\varphi_{1}, \varphi_{2}\right)$, respectively; III has both a VBM and a CBM in this range. Accordingly, these NMs have iFMOs and thus are potential catalysts. In contrast, VI, VII, VIII, X, and XI have no iFMOs and thus are not the potential catalysts. Because the FMO energies of NMs can be measured by experiments or calculated by DFT, this energy level principle could be easily implemented for screening NMs toward $\mathrm{O}_{2}{ }^{\bullet-}$ scavenging catalysts.

To verify the energy level principle, we have calculated the electronic density of states (DOSs) for all materials listed in Table 1, whose SOD-like catalytic activities have been experimentally confirmed before. For these calculations, graphene has been used as the model of $\mathrm{sp}^{2}$ carbons. Reportedly, $\mathrm{MoS}_{2}$ contains sulfur vacancies ${ }^{37}$. Therefore, $\mathrm{MoS}_{2-\mathrm{x}}$ with a reduced number of sulfur has been used for the calculation (for computational method, see Supplementary Fig. 2, Supplementary Table 1, and Supplementary Method). The calculated results are shown in Fig. $2 \mathrm{c}$ and Supplementary Fig. 3a. $\mathrm{NiO}, \mathrm{MoS}_{2-\mathrm{x}}, \mathrm{Mn}_{3} \mathrm{O}_{4}, \mathrm{Co}_{3} \mathrm{O}_{4}, \mathrm{~V}_{2} \mathrm{C}, \mathrm{Nb}_{2} \mathrm{C}$, $\mathrm{Au}$, and $\mathrm{Pd}$ indeed have FMOs located in the energy window $(-0.16 \mathrm{~V}, 0.94 \mathrm{~V})$. The Fermi level of graphene is $-0.19 \mathrm{~V}$, which is close to $-0.16 \mathrm{~V}$. These results excellently support the energy level principle. The CBM of $\mathrm{MnO}_{2}$ has energy more positive than $\varphi_{2}$; therefore, $\mathrm{MnO}_{2}$ will probably oxidize $\mathrm{O}_{2}{ }^{--}$to form $\mathrm{O}_{2}, \mathrm{H}_{2} \mathrm{O}$, and $\mathrm{MnO}_{2-\mathrm{x}}$ in the presence of $\mathrm{H}^{+}$rather than catalyze the disproportionation of $\mathrm{O}_{2}{ }^{-}$. In contrast, the VBM of $\mathrm{MnO}$ has energy more negative than $\varphi_{1}$; therefore, $\mathrm{MnO}$ will probably reduce $\mathrm{O}_{2} \cdot-$ to form $\mathrm{H}_{2} \mathrm{O}_{2}$ and $\mathrm{MnO}_{1+\mathrm{x}}$ in the presence of $\mathrm{H}^{+}$. We reason that the SOD-like activities experimentally found for them are actually originated from the modified structures $\mathrm{MnO}_{2-\mathrm{x}}$, and
$\mathrm{MnO}_{1+\mathrm{x}}$, respectively. Similarly, the SOD-like activity of $\mathrm{CeO}_{2}$ is originated from the modified structure $\mathrm{CeO}_{2-\mathrm{x}}{ }^{26,32}$. Pt does not have any iFMO, which can be ascribed to that $\mathrm{Pt}$ particles practically expose irregular surfaces unlike the Pt(111) used for the calculation. These results suggest the potential power of the principle to investigate the in-situ active structures for the catalysts.

Besides the support by computation, such an energy level principle has also been supported by previous experimental results on the redox potentials of the materials. For example, Tsai et al. reported the SOD-like activity of $\mathrm{sp}^{2}$ carbon $\mathrm{NMs}$, including single-walled carbon nanotubes and nanographene ${ }^{11}$. These researchers found that the reduction potential of nanographene was $0.40 \mathrm{~V}$, which was exactly located in the range from $-0.16 \mathrm{~V}$ to $0.94 \mathrm{~V}$ (Fig. 1b), supporting our energy level principle ${ }^{11}$. Recently, Wei et al. ${ }^{28}$ have reported the SOD-like activities for $\mathrm{V}_{2} \mathrm{C}$ MXene. The reduction potential of $\mathrm{V}_{2} \mathrm{C}$ has been determined to be $-0.11 \mathrm{~V}^{28}$, which is in good agreement with our energy level principle.

The energy level principle provides not only the criterion to screen out NMs as potential catalysts but also new insight into the catalysis mechanism. Because the iFMOs of NMs II and V are the unoccupied FMOs (i.e., the lowest unoccupied molecular orbitals, LUMOs), the catalysis follows a LUMO-mediated mechanism (Fig. 2d):

$$
\begin{aligned}
& \mathrm{O}_{2}^{\bullet-}+\mathrm{NM}=\mathrm{O}_{2}+\mathrm{NM}^{-} \\
& \mathrm{O}_{2}^{\bullet-}+2 \mathrm{H}^{+}+\mathrm{NM}^{-}=\mathrm{H}_{2} \mathrm{O}_{2}+\mathrm{NM}
\end{aligned}
$$

The NM is first reduced by one $\mathrm{O}_{2}{ }^{--}$and then oxidized back to its original state by another $\mathrm{O}_{2}{ }^{--}$, with negatively charged $\mathrm{NM}^{-}$as the intermediate. This CBM-mediated mechanism has been experimentally observed for the SOD-like activity of $\mathrm{sp}^{2}$ carbon $\mathrm{NMs}^{11}$ having unoccupied iFMOs, which agrees with this prediction. By contrast, the activity of NM-I and NM-IV is mediated by occupied FMOs (i.e., the highest occupied molecular orbitals, HOMOs) and thus follows a HOMO-mediated mechanism (Fig. 2e):

$$
\begin{aligned}
& \mathrm{O}_{2}^{\bullet-}+2 \mathrm{H}^{+}+\mathrm{NM}=\mathrm{H}_{2} \mathrm{O}_{2}+\mathrm{NM}^{+} \\
& \mathrm{O}_{2}^{\bullet-}+\mathrm{NM}^{+}=\mathrm{O}_{2}+\mathrm{NM}
\end{aligned}
$$

The NM is first oxidized by one $\mathrm{O}_{2}{ }^{--}$and then reduced back by another with positively charged $\mathrm{NM}^{+}$as the intermediate. Having both occupied and unoccupied FMOs as the iFMOs, the activities of NM-III and NM-IX follow both mechanisms with the overall neutral intermediate. The HOMO-mediated mechanism has not been experimentally reported before and deserves attention in the future.

Using the energy level principle, we now analyze the iFMOs for the NMs in Table 1 to predict the mechanisms of their SOD-like activities, which have been rarely studied at the microscopic level. The results of Fig. $2 c$ and Supplementary Fig. 3a predict the following new knowledge. The iFMO of NiO is its VBM; those of $\mathrm{MoS}_{2-\mathrm{x}}, \mathrm{Mn}_{3} \mathrm{O}_{4}$, and $\mathrm{Co}_{3} \mathrm{O}_{4}$ are their CBMs. Therefore, $\mathrm{NiO}$ has an occupied iFMO, following the HOMO-mediated mechanism. $\mathrm{MoS}_{2-\mathrm{x}}, \mathrm{Mn}_{3} \mathrm{O}_{4}$, and $\mathrm{Co}_{3} \mathrm{O}_{4}$ have unoccupied iFMOs, following the LUMO-mediated mechanism. For metals, the Fermi energies with respect to the vacuum energy are known as work function $\left(W_{\mathrm{f}}\right)$. Therefore, a $W_{\mathrm{f}}$-version of the energy level principle has been further derived, which also supports the principle (Supplementary Note 1 and Supplementary Fig. 3b).

To computationally verify the above-predicted mechanisms, we located the key intermediate and transition state structures involved in the dismutation of $\mathrm{O}_{2}{ }^{-}$on the surfaces of $\mathrm{NiO}(100)$ and $\mathrm{MoS}_{2-\mathrm{x}}$ using DFT calculations. As can be seen from Fig. $2 \mathrm{f}$ and $2 \mathrm{~g}$, the kinetically favorable pathways for the dismutation of $\mathrm{O}_{2}{ }^{-}-$on $\mathrm{NiO}(100)$ and $\mathrm{MoS}_{2-\mathrm{x}}$ indeed follow the HOMO- and 
a

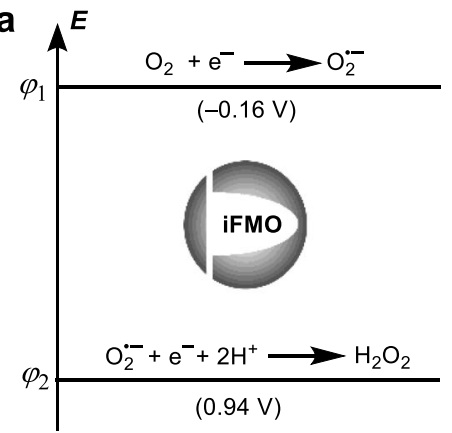

b

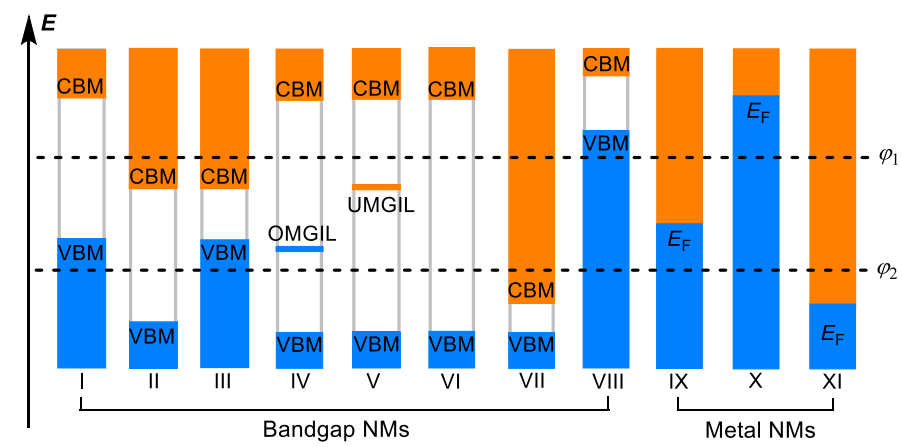

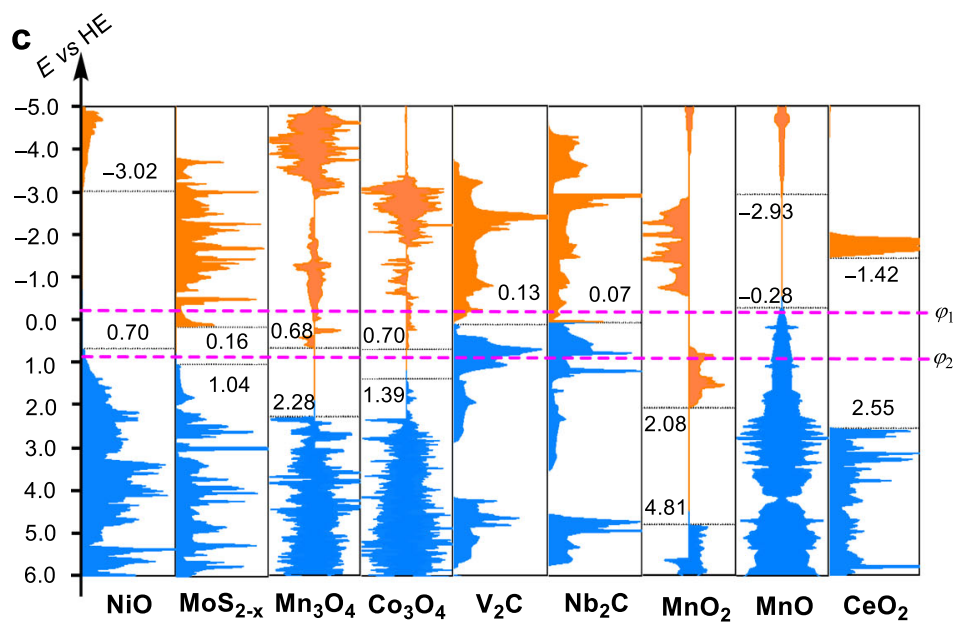

d

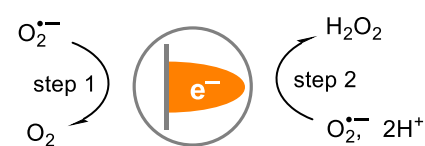

LUMO-mediated mechanism e

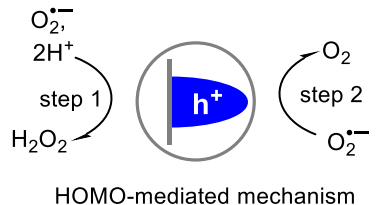

f

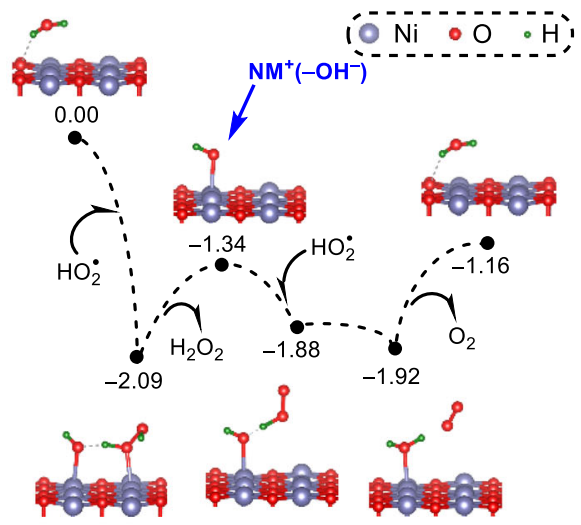

g

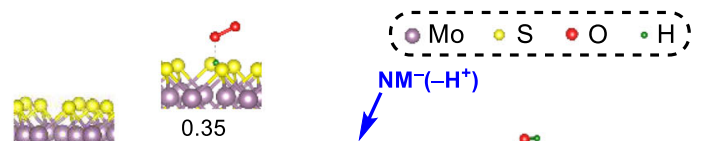

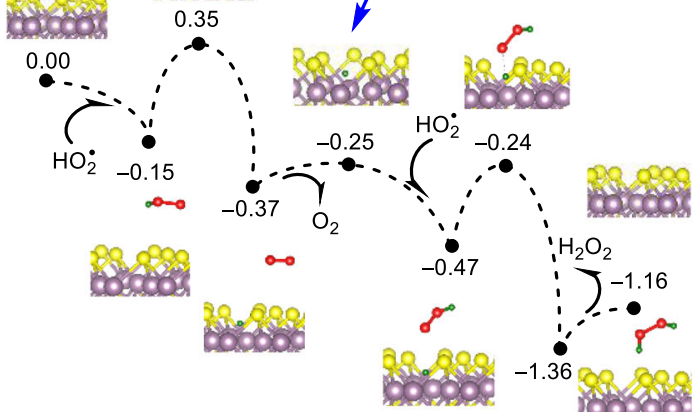

Fig. 2 The energy level principle for $\mathbf{N M s}$ to catalytically scavenge $\mathbf{O}_{\mathbf{2}}{ }^{\bullet-}$. a The model for nanomaterials, where intermediate frontier molecular orbital (iFMO) means the FMO with energy located in the range $\left(\varphi_{1}, \varphi_{2}\right)$. $\mathbf{b}$ Nanomaterials having different types of FMOs with respect to the potentials $\varphi_{1}$ and $\varphi_{2}$. c Calculated electronic density of states with the energies of FMOs marked. (d, e) Diagrams for the LUMO- and HOMO-mediated catalytic mechanisms. ( $\mathbf{f}, \mathbf{g}$ ) Reaction energy profiles corresponding to the superoxide dismutase-like catalyzes of $\mathrm{NiO}(100)$ and $\mathrm{MoS}_{2-x}$, respectively; the intermediates with the ionic nature are labeled. In $(\mathbf{f}, \mathbf{g})$ some water molecules as explicit solvents and the kinetically unfavorable pathways are not shown for clarity; the complete energy profiles are given in Supplementary Fig. 1. In $\mathbf{b}-\mathbf{d}$, and $\mathbf{e}$, the blue and orange colors represent the occupied and unoccupied molecular orbitals, respectively.

LUMO-mediated mechanisms, respectively. On $\mathrm{NiO}(100)$, the first protonated $\mathrm{O}_{2}^{\bullet-}$ (i.e., $\mathrm{HO}_{2}{ }^{\bullet}$ ) takes the hydrogen atom from the $\mathrm{H}_{2} \mathrm{O}$ adsorbate to form the $\mathrm{H}_{2} \mathrm{O}_{2}$ molecule, which oxidizes the NM by forming the intermediate $\mathrm{NM}^{+}\left(-\mathrm{OH}^{-}\right)$. The second $\mathrm{HO}_{2}$. transfers its hydrogen to the $\mathrm{HO}$ adsorbate to generate the $\mathrm{O}_{2}$ molecule, which reduces the NM back to the original state (Fig. 2f). On $\mathrm{MoS}_{2-\mathrm{x}}, \mathrm{HO}_{2}{ }^{-}$first passes its hydrogen to the sulfur of $\mathrm{MoS}_{2-\mathrm{x}}$, reducing the $\mathrm{NM}$ by forming the intermediate $\mathrm{NM}^{-}\left(-\mathrm{H}^{+}\right)$. The second $\mathrm{HO}_{2}{ }^{\bullet}$ takes the hydrogen away, oxidizing the $\mathrm{NM}$ to its original state (Fig. $2 \mathrm{~g}$ ). Therefore, the results of Fig. $2 \mathrm{f}$, g excellently support the predicted mechanisms. The energy profiles in Fig. $2 \mathrm{f}, \mathrm{g}$ also suggest that the SOD-like catalysts have only very small energy barriers $(<0.50 \mathrm{eV})$, which means that the catalysts are controlled by thermodynamics. This explains why the energy level principle, which only reflects the thermodynamics of the half-reactions, can successfully predict the catalytic activity of NMs.

Adsorption energy principle. We now develop a model to describe the competition of the side reactions with the target dismutation of $\mathrm{O}_{2}^{\cdot-}$ on NMs. In Fig. 3a, the target reaction is illustrated as (i), and the possible side reactions are illustrated as (ii-v). Denoting the Gibbs free energy $(G)$ changes in these five reactions as $\Delta_{\mathrm{r}} G_{\mathrm{i}}(\mathrm{i}=1-5)$, the molar fraction $x_{1}$ for $\mathrm{O}_{2}^{\cdot-}$ to 

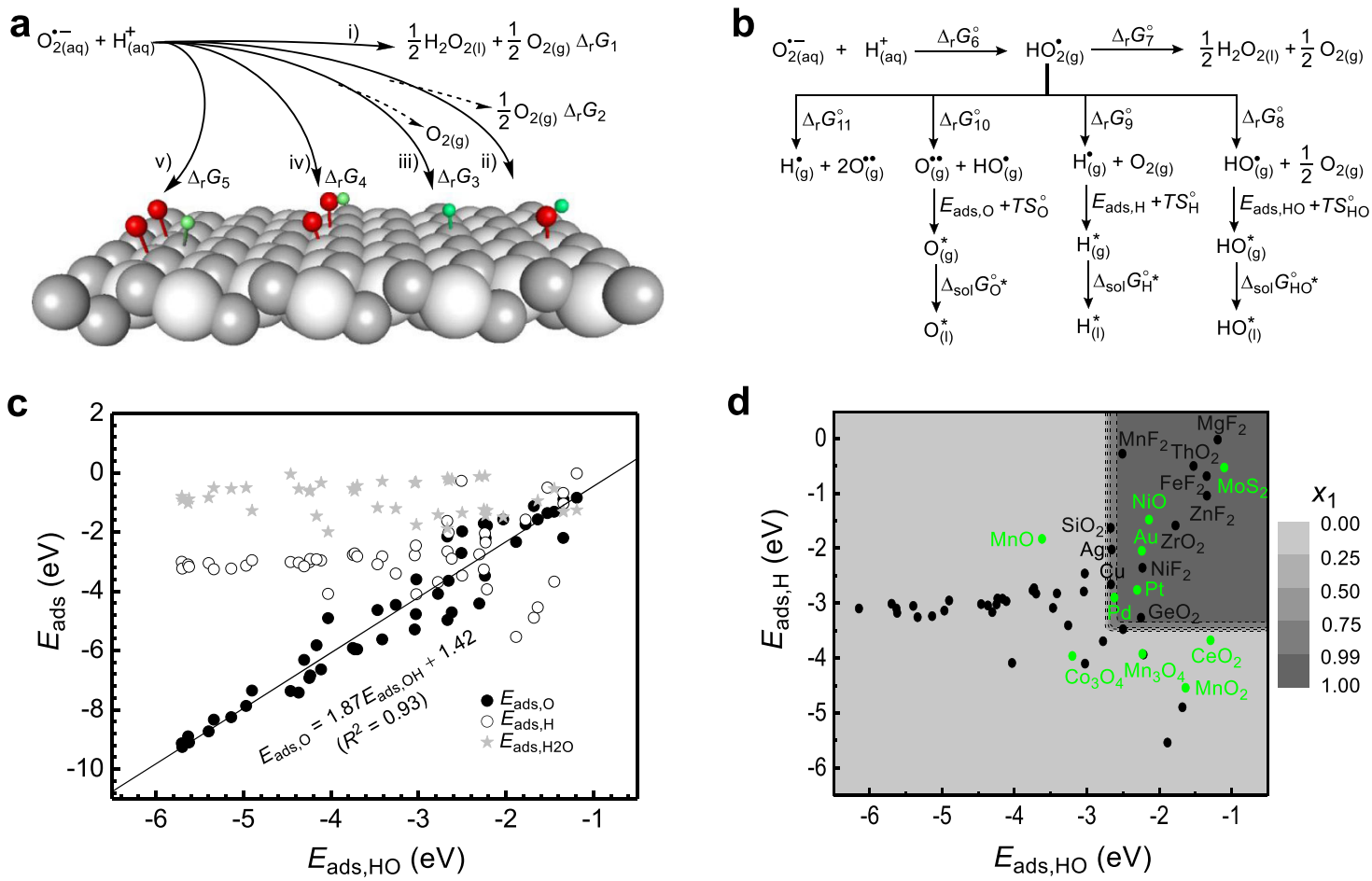

Fig. 3 The adsorption energy principle for $\mathbf{N M s}$ to catalytically scavenge $\mathbf{O}_{\mathbf{2}}{ }^{\bullet-}$. a The dismutation (i) and competitive side reactions (ii- $-\mathrm{v}$ ) of $\mathrm{O}_{2}{ }^{\bullet-}$ that may occur on the surface of nanomaterials. $\mathbf{b}$ The Hess cycles for reactions (i-v). c The adsorption energies of $\mathrm{O}^{\bullet \bullet}, \mathrm{H}^{\bullet}$, and $\mathrm{H}_{2} \mathrm{O}$ with respect to that of $\mathrm{HO} \cdot$ on various material surfaces. $\mathbf{d}$ The contour plot of the partition function $x_{1}$ as a function of $E_{\mathrm{ads}, \mathrm{HO}}$ and $E_{\mathrm{ads}, \mathrm{H}}$. In $\mathbf{a}, \mathrm{O}$ and $\mathrm{H}$ are shown in red and green, respectively; the other atoms are of the substrate. In $\mathbf{d}$, the filled green and black circles represent nanomaterials whose superoxide dismutase-like activities have and have not been experimentally reported.

undergo reaction (i) when reaching thermodynamic equilibrium can be expressed with the following partition function:

$$
x_{1}=\frac{e^{-\frac{\Delta_{\mathrm{r}} G_{1}}{R T}}}{\sum_{i=1}^{5} e^{-\frac{\Delta_{\mathrm{r}} G_{i}}{R T}}}
$$

In Eq. (2), $e, R$, and $T$ are Euler's number, the universal gas constant, and temperature, respectively. The target reaction is dominant, meaning that over $50 \%$ of $\mathrm{O}_{2}{ }^{--}$undergoes reaction (i). Therefore, we propose $x_{1}>0.5$ as the second criterion for screening NMs as $\mathrm{O}_{2}{ }^{\bullet-}$ scavenging catalysts.

To derive a simpler screening criterion from Eq. (2), the mathematical operations described in the Method and Supplementary Method sections were conducted. Briefly, the calculation of $x_{1}$ at any $\mathrm{pH}$ needs to calculate $\Delta_{\mathrm{r}} G_{\mathrm{i}}(\mathrm{i}=1-5)$ at the $\mathrm{pH}$. To calculate $\Delta_{\mathrm{r}} G_{\mathrm{i}}(\mathrm{i}=1-5)$ using the standard thermodynamic data that can be consulted from the chemistry handbooks, the Hess cycles of Fig. $3 \mathrm{~b}$ have been constructed. The result suggests that $x_{1}$ is a function of three variables, $E_{\mathrm{ads}, \mathrm{HO}}, E_{\mathrm{ads}, \mathrm{O}}$, and $E_{\mathrm{ads}, \mathrm{H}}$, which represent the energy changes for the adsorptions of $\mathrm{HO}^{*}, \mathrm{O}^{\bullet}$, and $\mathrm{H}^{\bullet}$ on the material surfaces, respectively. Because of the linear relationship between $E_{\mathrm{ads}, \mathrm{HO}}$ and $E_{\mathrm{ads}, \mathrm{O}}$ shown in Fig. $3 \mathrm{c}, x_{1}$ turns to a function of only two variables, $E_{\mathrm{ads}, \mathrm{HO}}$, and $E_{\mathrm{ads}, \mathrm{H}}$. Figure $3 \mathrm{~d}$ plots the variation in $x_{1}$ with $E_{\mathrm{ads}, \mathrm{HO}}$ and $E_{\mathrm{ads}, \mathrm{H}}$. From Fig. $3 \mathrm{~d}$, the criterion $x_{1}>0.5$ becomes

$$
E_{\mathrm{ads}, \mathrm{HO}}>-2.7 \mathrm{eV} \text { and } E_{\mathrm{ads}, \mathrm{H}}>-3.4 \mathrm{eV}
$$

Therefore, Eq. (3) is the second criterion for screening NMs as $\mathrm{O}_{2}{ }^{-}-$scavenging catalysts under the condition that $T=298.15 \mathrm{~K}$ and $\mathrm{pH}=7$.

The adsorption energy principle reasonably explains the SODlike activity for $\mathrm{Au}^{15}, \mathrm{Pd}^{16}, \mathrm{Pt}^{17}, \mathrm{NiO}^{25}$, and $\mathrm{MoS}_{2}^{27}$, which are located in the region with $x_{1}>0.5$ (Fig. 3d). However, $\mathrm{CeO}_{2}{ }^{26}$, $\mathrm{MnO}^{18}, \mathrm{MnO}_{2}{ }^{20}, \mathrm{Mn}_{3} \mathrm{O}_{4}{ }^{22}$, and $\mathrm{Co}_{3} \mathrm{O}_{4}{ }^{24}$ are beyond the region, although their SOD-like activities have been experimentally demonstrated. Such inconsistency may be ascribed to the that the practical surfaces of these NMs exhibiting activity are different from the slab models used for calculating the $E_{\mathrm{ads}, \mathrm{HO}}$ and $E_{\mathrm{ads}, \mathrm{H}}$. Unfortunately, the exact surface structures of NMs in water are usually difficult to characterize because they may simultaneously expose multiple surfaces ${ }^{40}$, and surface reconstructions may drastically occur in water ${ }^{41}$. We believe that $\mathrm{NMs}$ such as $\mathrm{CeO}_{2}$, $\mathrm{MnO}, \mathrm{MnO}_{2}, \mathrm{Mn}_{3} \mathrm{O}_{4}$, and $\mathrm{Co}_{3} \mathrm{O}_{4}$ will enter the region $x_{1}>0.5$ when their exact surface structures are determined and used for calculating the adsorption energies. This point is already supported by the case of $\mathrm{CeO}_{2}$. The $E_{\mathrm{ads}, \mathrm{H}}$ of $\mathrm{CeO}_{2}$ calculated using the defect-free (111) surface is $-3.68 \mathrm{eV}$. However, practical nanoceria contains oxygen vacancies 38,39 and thus are more chemically reductive. Therefore, the practical value of $E_{\mathrm{ads}, \mathrm{H}}$ is more positive, pushing $\mathrm{CeO}_{2}$ into the region with $x_{1}>0.5$. These results suggest that Eq. (3) is a simple but powerful criterion that is able to screen our NMs on which the target catalytic reaction is more thermodynamically completive than unwanted side reactions.

Experimental verification. To verify the above screening principles, metal-organic framework (MOF) compounds MIL-53(Fe)$\mathrm{X}\left(\mathrm{X}=\mathrm{NH}_{2}, \mathrm{CH}_{3}, \mathrm{H}, \mathrm{HO}, \mathrm{F}, \mathrm{Cl}, \mathrm{Br}\right.$, and $\left.\mathrm{NO}_{2}\right)$ were synthesized and their activities of scavenging $\mathrm{O}_{2}{ }^{-}-$were investigated by the combination of experiments and computations. As seen from Fig. 4a, the structures of these MOFs differ from each other in the linker substituents X. The Hammett $\sigma_{\mathrm{m}}$ values, which characterize the electron-withdrawing ability of the substituents, increase in the order $\mathrm{NH}_{2}<\mathrm{CH}_{3}<\mathrm{H}<\mathrm{HO}<\mathrm{F}<\mathrm{Cl}<\mathrm{Br}<\mathrm{NO}_{2}$. To determine whether these MOFs satisfy the energy level criterion 
a

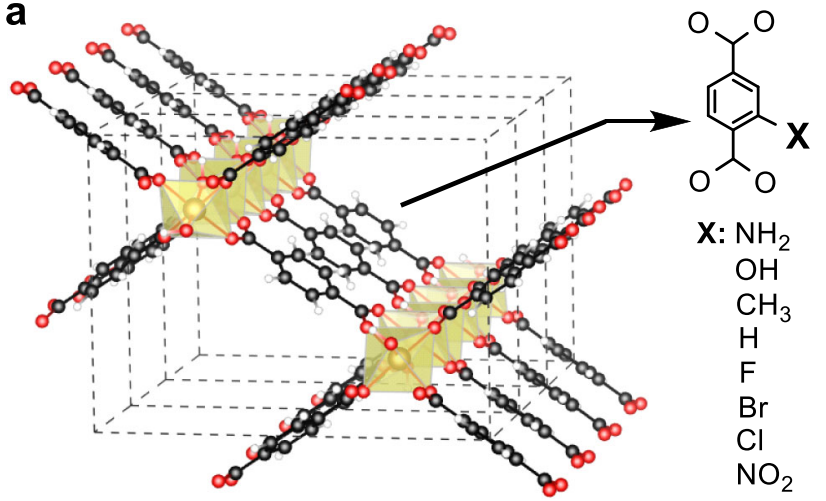

C

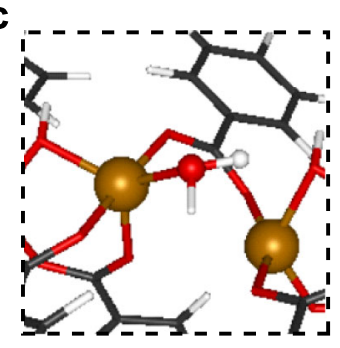

d

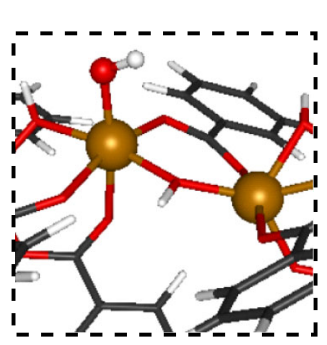

b

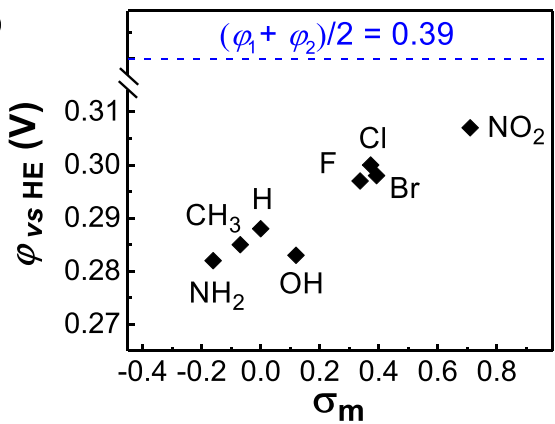

e

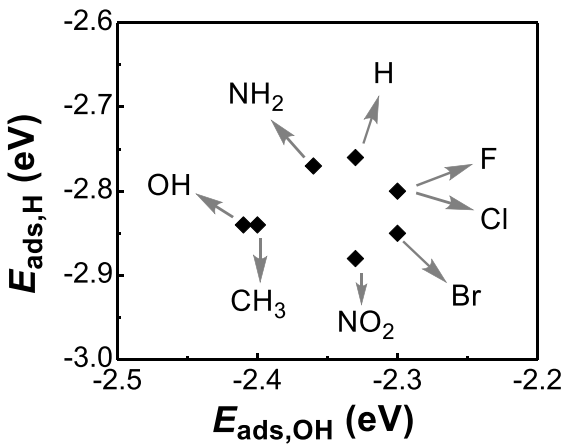

f

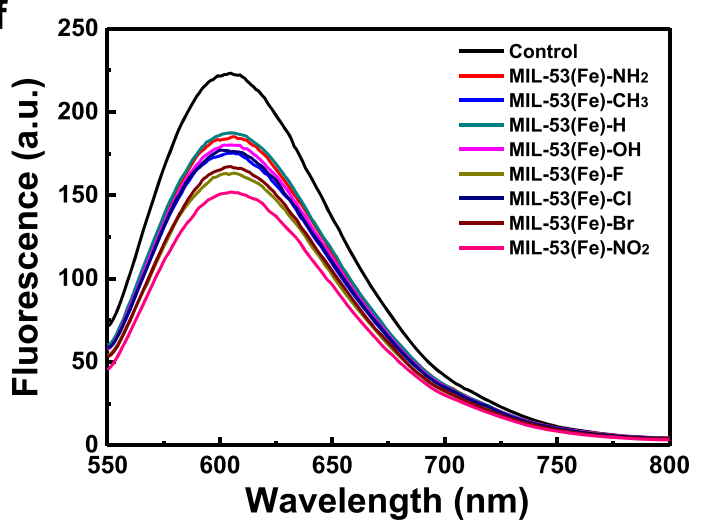

g

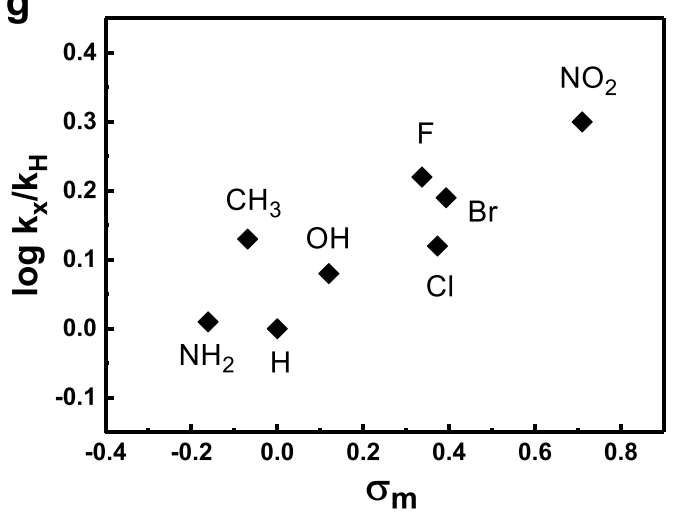

Fig. 4 Experimental verification of the screening principles. a Structural diagram of MIL-53(Fe)-X. b Reduction potentials experimentally determined for MIL-53(Fe)-X with respect to the potential of hydrogen electrode (HE) at $\mathrm{pH}=7$. c Partial structure of MIL-53(Fe)-H with an $\mathrm{H}$ adsorbate. d Partial

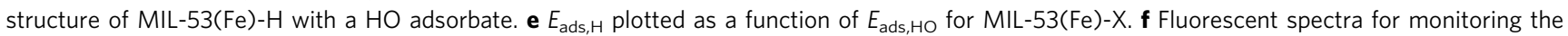
superoxide dismutase-like activities of MIL-53(Fe)-X. $\mathbf{g}$ Superoxide dismutase-like activities of MIL-53(Fe)-X plotted as a function of Hammett $\sigma_{\mathrm{m}}$ values. In $\mathbf{a}$, c, and $\mathbf{d}$, atoms $\mathrm{C}, \mathrm{O}, \mathrm{Fe}$, and $\mathrm{H}$ are shown in black, red, brown, and white, respectively.

(Eq. (1)), their reduction potentials were measured using the cyclic voltammetry technique ${ }^{42}$. Fig. $4 \mathrm{~b}$ plots the measured reduction potentials as a function of $\sigma_{\mathrm{m}}$. The reduction potentials and the $\sigma_{\mathrm{m}}$ values have similar variation tendencies, which is in agreement with the knowledge that a stronger electronwithdrawing substituent leads to a high electron affinity of the material $^{42}$. Importantly, the reduction potentials vary from $0.28 \mathrm{~V}$ (for $\mathrm{X}=\mathrm{NH}_{2}$ ) to $0.31 \mathrm{~V}$ (for $\mathrm{X}=\mathrm{NO}_{2}$ ), which are exactly located in the range from $-0.16 \mathrm{~V}$ to $0.94 \mathrm{~V}$. Therefore, all the eight MOFs satisfy the energy level criterion. To determine whether these MOFs satisfy the adsorption energy criterion Eq. (3), the $E_{\text {ads, HO }}$ and $E_{\text {ads, H }}$ values at the defective sites of the MOFs were calculated using the DFT method. The most energetically favorable adsorption sites for $\mathrm{H}^{\bullet}$ and $\mathrm{HO}^{\bullet}$ are the bridge oxygen and iron atoms, respectively (Fig. $4 \mathrm{c}$, d). All the calculated $E_{\mathrm{ads}, \mathrm{HO}}$ values are more negative than $-2.3 \mathrm{eV}$, and those of $E_{\mathrm{ads}, \mathrm{H}}$ more negative than $-2.7 \mathrm{eV}$. Namely, all the eight MOFs also satisfy the adsorption energy level criterion, and thus all the MOFs are predicted to have the activity of catalytically scavenging $\mathrm{O}_{2}{ }^{-}-$.
The above prediction encouraged us to further investigate the SOD-like activities of MIL-53(Fe)-X MOFs experimentally. The $\mathrm{O}_{2}{ }^{--}$scavenging abilities of MIL-53(Fe)-X MOFs were characterized by monitoring the fluorescent spectra of ethidium, the product of $\mathrm{O}_{2}{ }^{--}$and its specific probe hydroethidine. As shown in Fig. 4f, in the absence of MIL-53(Fe)-X MOFs, the hydroethidine could react with $\mathrm{O}_{2}{ }^{-}$to generate the strongest fluorescence with a peak located around $600 \mathrm{~nm}$. With the introduction of MIL53(Fe)-X MOFs rather than their corresponding ligands (Supplementary Fig. 4), the fluorescent intensity of ethidium significantly decreased, whereas the one with MIL-53(Fe)- $\mathrm{NO}_{2}$ gave the lowest intensity. This result illustrated that the addition of these MIL53(Fe)-X MOFs could eliminate $\mathrm{O}_{2}{ }^{--}$amount, and thus reducing the fluorescent intensities of ethidium. The SOD-like activities of MIL-53(Fe)-X MOFs were also plotted as a function of $\sigma_{\mathrm{m}}$ values (Fig. 4g). And a similar change tendency as the one in Fig. $4 \mathrm{~b}$ was observed, where MIL-53(Fe)- $\mathrm{NH}_{2}$ with the reduction potential farthest and MIL-53(Fe)- $\mathrm{NO}_{2}$ with the reduction potential closest to the midpoint of $\varphi_{1}$ and $\varphi_{2}(0.39 \mathrm{~V})$ gave the worst and best 
SOD-like activities. This activity order supported the prediction that NMs with $E_{\mathrm{iFMO}}=\left(\varphi_{1}+\varphi_{2}\right) / 2$ have the maximized catalytic efficiency. While for another MIL-47(V)-X $\left(\mathrm{X}=\mathrm{H}, \mathrm{NH}_{2}\right.$, and $\left.\mathrm{Br}\right)$ MOF, their reduction potentials were even lower than that of MIL-53(Fe)- $\mathrm{NH}_{2}$ (Supplementary Fig. 5). And our previous work showed that MOFs including MIL-47(V)- $\mathrm{NH}_{2}, \mathrm{MIL}-47(\mathrm{~V})-\mathrm{H}$, and MIL-47(V)-Br indeed exhibited much weaker and even negligible SOD-like activities ${ }^{43}$. Furthermore, DFT calculations suggested that the $E_{\mathrm{ads}, \mathrm{HO}}$ and $E_{\mathrm{ads}, \mathrm{H}}$ of these MIL-47(V) MOFs were about $-0.76 \mathrm{eV}$ and more $-4.25 \mathrm{eV}$ (Supplementary Method and Supplementary Figs. 6 and 7), respectively, disobeying the adsorption energy criterion Eq. (3). This finding confirmed the negligible SOD-like activities of MIL-47(V)-X $\left(\mathrm{X}=\mathrm{H}, \mathrm{NH}_{2}\right.$, and $\mathrm{Br}) \mathrm{MOF}$, consistent with the guidance of the above principle. The principle was further verified by the different SOD-like activities of ceria particles that were synthesized under the same condition except at different temperatures: $0,30,60$, and $90^{\circ} \mathrm{C}$. The former two ceria particles had markedly stronger activities than the latter, which exactly agreed with the experimental result that the former had the iFMO but the latter did not (see Supplementary Note 2 and Supplementary Figs. 8-11). Therefore, the results here not only demonstrated the above screening principles could predict the SOD-like activities of MOFs, but also verified the validity and generality of the principles.

Computational screening of antioxidants from 2D materials. We now use the above screening principles, Eq. (1) and Eq. (3), to screen NMs with intrinsic SOD-like catalytic activity. Because two-dimensional (2D) materials have large surface areas, which will serve as potential catalytically active sites, we focus our attention on 2D materials. Thygesen and coworkers established the Computational 2D Materials Database (C2DB), which deposits structural, elastic, thermodynamic, electronic, optical, and magnetic properties for a total of $38142 \mathrm{D}$ materials obtained by DFT calculations ${ }^{44}$. This database provides an excellent platform for the modeling and design of $2 \mathrm{D}$ materials without redundant calculations.

Here, we will screen out stable NMs belonging to type I or II from the $2 \mathrm{D}$ material library. We further restrict our screening within the subset composed of no more than two elements because NMs consisting of fewer elements will be more suitable for mechanistic studies in the future. The screening procedure is shown in Fig. 5. A total of 370 materials among the 3814 passed the first-step screening. These materials are all composed of no more than two elements $\left(N_{\text {element }} \leq 2\right)$, have considerable thermodynamic stability $\left(\Delta H_{\text {hull }}<\right.$ $0.2 \mathrm{eV} /$ atom) and kinetic stability $\left(\tilde{\omega}_{\min }^{2}>10^{-5} \mathrm{eV} / \AA^{2}\right)$, and have nonzero electronic bandgaps calculated with the Heyd-Scuseria-Ernzerhof (HSE) method $\left(E_{\mathrm{g}, \mathrm{HSE}}>0\right)^{44}$. A total of 126 of the 370 passed the second-step screening. These materials have only one type of iFMO, either a CBM or a VBM, whose energy is located in the range $\left(\varphi_{1}, \varphi_{2}\right) .121$ among the 126 passed the thirdstep screening, which had $E_{\text {ads, } \mathrm{HO}}>-2.7 \mathrm{eV}$ and $E_{\text {ads, } \mathrm{H}}>-3.4 \mathrm{eV}$. These 121 materials are thus predicted to have intrinsic SOD-like catalytic activities. These results have demonstrated that the screening principles can be easily implemented in computer programs for the high-throughput screening of NMs with intrinsic SOD-like activity. Among these materials, T-phase transition metal dichalcogenides (TTMDCs, $\mathrm{PtS}_{2}{ }^{45}, \mathrm{ZrS}_{2}{ }^{46}, \mathrm{ZrSe}_{2}{ }^{46}, \mathrm{SnS}_{2}{ }^{47}, \mathrm{HfS}_{2}{ }^{48}$ ) and H-TMDCs $\left(\mathrm{MoTe}_{2}{ }^{49}, \mathrm{WSe}_{2}{ }^{50}, \mathrm{WTe}_{2}{ }^{51}, \mathrm{VS}_{2}{ }^{52}\right)$ have been experimentally reported. They existed in the form of single layers supported on substrates or a few layers in solutions ${ }^{53-57}$. The SOD-like activities of these nine single-layer TMDC structures have been computationally investigated, and the results match well with the prediction (see Supplementary Table 2, Supplementary Note 3, and Supplementary Figs. 12-14). Therefore, the screening performed on $2 \mathrm{D}$ materials is likely to stimulate the application of these materials as novel SOD mimics provided that the high-yield synthesis of these single layers is achieved.

It's worth noting that the principles are proposed for ideal material surfaces with explicit atomic structures. However, real NMs usually have inhomogeneous morphologies and ambiguous structural configurations. In addition, because the SOD-like catalysis occurs in aqueous solutions, other molecules present in the solvents may cause irreversible structural modifications to the materials, changing their FMO energies and surface affinities. The different aqueous dispersibility of materials may also influence their practical catalytic performances. This complexity of NMs in real situations should be considered when linking the predicted results to experiments.

In summary, two principles governing the catalytic activity of NMs mimicking that of SOD have been revealed by computationally studying the microscopic thermodynamics and kinetics of the catalytic processes. The energy level principle suggests the critical role of the iFMO in transferring electrons for the catalysis, which can be used to predict whether both half-reactions of the catalytic dismutation of $\mathrm{O}_{2}{ }^{\cdot-}$ are thermodynamically favorable. This principle suggests the first criterion for screening NMs with the SOD-like activity: the NMs should have at least one iFMO, namely, the FMO with energy located in between $\left(\varphi_{1}, \varphi_{2}\right)$. Because the catalytic mechanism critically depends on whether the iFMO is occupied by electrons or not, this principle determines whether the SOD-like catalysis of NMs follows the HOMO- or the LUMO-mediated mechanism. The adsorption energy principle is based on the thermodynamic partition function and determines whether the target catalytic reaction occurring on the NMs is more thermodynamically competitive than the undesired side reactions. This principle suggests the second criterion for the screening, $E_{\mathrm{ads}, \mathrm{HO}}>-$ $2.7 \mathrm{eV}$ and $E_{\mathrm{ads}, \mathrm{H}}>-3.4 \mathrm{eV}$ at $\mathrm{pH} 7$ and at the level of theory used for the computations. Both principles have received support from the previous results of NMs showing the SOD-like catalytic activity, giving an in-depth explanation of the results. The ability of the principles to predict the SOD-like activities of MOFs was further verified by our experimental results. The screening criteria derived from the principles can be easily implemented into computer programs, and they are used to computationally screen the NMs with the intrinsic SOD-like activity from the database of $2 \mathrm{D}$ materials. The results provide a systematic view of the antioxidant property of NMs and the method for the computational design and screening of NMs as novel SOD mimics.

\section{Methods}

DFT calculations. All NMs were computed using the projector augmented wave (PAW) method ${ }^{58}$ implemented in the Vienna Ab initio Simulation Package (VASP) ${ }^{59}$ The Perdew-Burke-Ernzerhof $(\mathrm{PBE})^{60}$ exchange-correlation functional with the generalized gradient approach (GGA) was applied. The plane-wave energy cutoff was set to $500 \mathrm{eV}$ for fluorites and $400 \mathrm{eV}$ for the other NMs. The GGA + U ${ }^{61}$ corrections using the formalism of Dudarev et $\mathrm{al}^{62}$. were also used to accurately describe the distribution of electrons on the NMs surfaces. When calculating the reaction energy profiles for $\mathrm{NiO}(111)$ and $\mathrm{MoS}_{2-\mathrm{x}}$, the water solvent effect was considered by an implicit solvation model using the VASPsol package developed by Kiran Mathew and Richard G.

Hennig ${ }^{63,64}$. A vacuum value of $15 \AA$ along the $z$-direction was set to separate the slab with an upward unit cell to avoid inveracious interactions. Gaussian smearing with a width of $0.05 \mathrm{eV}$ was used for the Fermi level. The total energy and force convergences were $10^{-5} \mathrm{eV}$ and $0.02 \mathrm{eV} / \AA$ for the local minimum of all potential surfaces. Some small molecules, such as $\mathrm{H}_{2} \mathrm{O}, \mathrm{H}_{2} \mathrm{O}_{2}, \mathrm{O}^{\bullet}, \mathrm{HO}^{*}, \mathrm{HO}_{2}{ }^{*}$, and $\mathrm{O}_{2}$, were calculated in a $15 \AA$ cubic lattice using the same parameters and convergence criteria as those for the rutile slabs. For the transition state search, the climbing image nudged elastic band method ${ }^{65}$ was used in conjunction with partial atomic fixation with a convergence of $10^{-4} \mathrm{eV}$ and $0.05 \mathrm{eV} / \AA$. More computational parameters, such as the model of every nanomaterial, the effect value of $U\left(U_{\text {eff }}\right)$, and the Brillouin zone k-points, are shown in Supplementary Data 1.

The adsorption energy $\left(E_{\text {ads }}\right)$ of a molecule on the slab is defined as follows:

$$
E_{\text {ads }, \text { mol }}=E_{\text {mol@slab }}-\left(E_{\text {slab }}+E_{\text {mol }}\right)
$$

where $E_{\text {slab}}, E_{\text {mol }}$, and $E_{\text {mol@slab }}$ are the total energies for the isolated ceria slab, isolated 


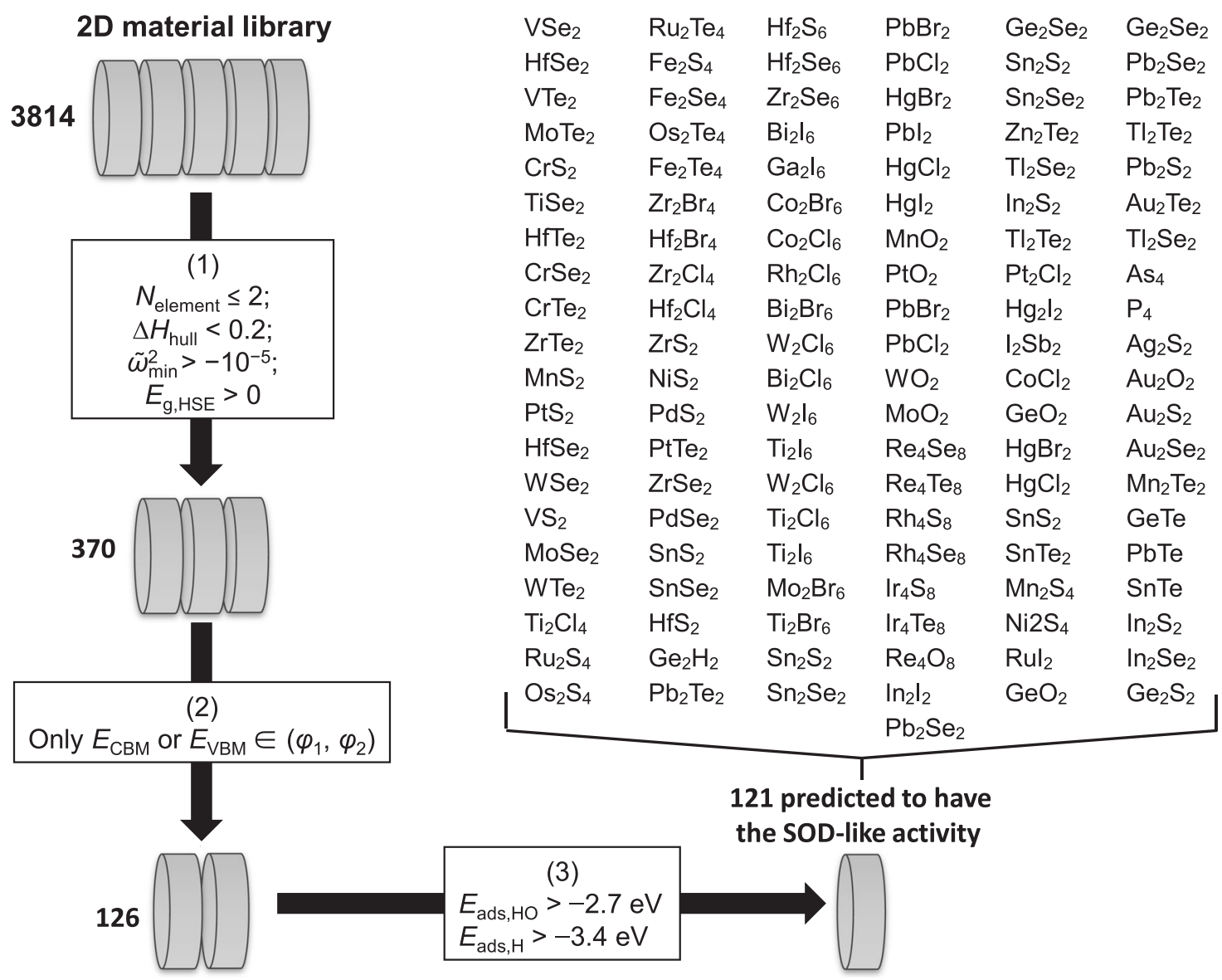

Fig. 5 Computational screening of two-dimensional nanomaterials as potential superoxide dismutase mimics. The screening was based on the library containing 3814 materials. Among them, 370 ones, which contained no more than two elements, had considerable thermodynamic and kinetic stabilities, and had an electronic bandgap, passed the first step of screening. 126 ones, which had conduction band minimum or valence band maximum as the only intermediate frontier molecular orbital, passed the second step of screening. 121 ones, which further satisfied the adsorption energy criterion, passed the second step of screening and were predicted to have intrinsic superoxide dismutase-like catalytic activity.

molecule, and ceria with the adsorbed molecule, respectively. The source data obtained by DFT calculations for Figs. 2-4 are present in Supplementary Data 2.

Derivation of the adsorption energy criterion. To calculate the partition function $x_{1}$ with Eq. (2), the values of $\Delta_{\mathrm{r}} G_{i}(i=1-5)$ should be calculated first. According to the Hess cycles of Fig. 3b, the $\Delta_{\mathrm{r}} G_{i}$ at any $\mathrm{pH}$ can be expressed as follows:

$$
\begin{gathered}
\Delta_{\mathrm{r}} G_{1}=\Delta_{\mathrm{r}} G_{6}^{\circ}+0.0592 \mathrm{pH}+\Delta_{\mathrm{r}} G_{7}^{\circ} \\
\Delta_{\mathrm{r}} G_{2}=\Delta_{\mathrm{r}} G_{6}^{\circ}+0.0592 \mathrm{pH}+\Delta_{\mathrm{r}} G_{8}^{\circ}+E_{\mathrm{ads}, \mathrm{HO}}+T S_{\mathrm{HO}}^{\circ}+\Delta_{\mathrm{sol}, 2} G_{\mathrm{HO}^{*}}^{\circ} \\
\Delta_{\mathrm{r}} G_{3}=\Delta_{\mathrm{r}} G_{6}^{\circ}+0.0592 \mathrm{pH}+\Delta_{\mathrm{r}} G_{9}^{\circ}+E_{\mathrm{ads}, \mathrm{H}}+T S_{\mathrm{H}}^{\circ}+\Delta_{\mathrm{sol}, 2} G_{\mathrm{H}^{*}}^{\circ} \\
\Delta_{\mathrm{r}} G_{4}=\Delta_{\mathrm{r}} G_{6}^{\circ}+0.0592 \mathrm{pH}+\Delta_{\mathrm{r}} G_{10}^{\circ}+E_{\mathrm{ads}, \mathrm{HO}}+T S_{\mathrm{HO}}^{\circ} \\
+\Delta_{\mathrm{sol}, 2} G_{\mathrm{HO}}^{\circ}+E_{\mathrm{ads}, \mathrm{O}}+T S_{\mathrm{O}}^{\circ}+\Delta_{\mathrm{sol}, 2}^{\circ} G_{\mathrm{O}^{*}}^{\circ} \\
\Delta_{\mathrm{r}} G_{5}=\Delta_{\mathrm{r}} G_{6}^{\circ}+0.0592 \mathrm{pH}+\Delta_{\mathrm{r}} G_{11}^{\circ}+E_{\mathrm{ads}, \mathrm{H}} \\
+T S_{\mathrm{H}}^{\circ}+\Delta_{\mathrm{sol}, 2} G_{\mathrm{H}^{*}}^{\circ}+2\left(E_{\mathrm{ads}, \mathrm{O}}+T S_{\mathrm{O}}^{\circ}+\Delta_{\mathrm{sol}, 2} G_{\mathrm{O}^{*}}^{\circ}\right)
\end{gathered}
$$

The detailed procedures to derive Eq. (4a-e) are presented in Supplementary Method. In the above equations, $\triangle_{\mathrm{r}} G_{i}^{\circ}(i=6-11)$ are defined in Fig. $3 \mathrm{~b}$ and also in the Supplementary Method. $S_{\mathrm{HO}}^{\circ}, S_{\mathrm{O}}^{\circ}$, and $S_{\mathrm{H}}^{\circ}$ are standard entropies of the radicals $\mathrm{HO}^{*}, \mathrm{O}^{*}$, and $\mathrm{H}^{*}$, respectively. $\triangle_{\mathrm{sol}, 2} G_{\mathrm{HO}^{*}}^{\circ}, \triangle_{\mathrm{sol}, 2} G_{\mathrm{O}^{*}}^{\circ}$, and $\triangle_{\text {sol }, 2} G_{\mathrm{H}^{*}}^{\circ}$ are the changes in the standard $G$ value associated with the solvation of adsorbates $\mathrm{HO}^{*}, \mathrm{O}^{*}$, and $\mathrm{H}^{*}$, respectively, from the gas phase in water (for their definition, see

the Supplementary Method). All these standard thermodynamic data necessary for the calculation of $\Delta_{\mathrm{r}} G_{i}(i=1-5)$ are summarized in Table 2. These results suggest that $\Delta_{\mathrm{r}} G_{i}(i=1-5)$ at any given $\mathrm{pH}$ are functions of three variables, $E_{\mathrm{ads}, \mathrm{HO}}$,

$E_{\text {ads, } \mathrm{HO}}$, and $E_{\text {ads, H}}$. Namely, the partition function $x_{1}$ is the function of these three variables.
To reduce the number of variables, the relationship between $E_{\mathrm{ads}, \mathrm{HO}}, E_{\mathrm{ads}, \mathrm{HO}}$, and $E_{\mathrm{ads}, \mathrm{H}}$ was further studied. We calculated the $E_{\mathrm{ads}, \mathrm{HO}}, E_{\mathrm{ads}, \mathrm{O}}$, and $E_{\mathrm{ads}, \mathrm{H}}$ for a series of material surfaces, which include the (100), (110), and (111) surfaces of transition metals and the (111) surfaces of the fluorites $\mathrm{MO}_{2}$ and the rutiles $\mathrm{MX}_{2}$ (for parameter settings of the calculations, see Supplementary Data 1). The results are plotted in Fig. $3 c$. As seen from this figure, $E_{\mathrm{ads}, \mathrm{HO}}$ and $E_{\mathrm{ads}, \mathrm{O}}$ have a good linear relation,

$$
E_{\text {ads }, \mathrm{O}}=1.87 E_{\text {ads }, \mathrm{HO}}+1.42
$$

A similar linear relation between $E_{\mathrm{ads}, \mathrm{HO}}$ and $E_{\mathrm{ads}, \mathrm{O}}$ has been reported previously by Nørskov ${ }^{67}, \mathrm{Liu}^{68}$, and coworkers, which can be ascribed to both $\mathrm{HO}^{*}$ and $\mathrm{O}^{*}$ preferring the same adsorption sites on the surfaces. Substituting $E_{\text {ads.O }}$ in Eq. (4d) and Eq. (4e) by Eq. (5), plugging the values of Table 2 into Eq. (4a-e), and taking $T=298.15 \mathrm{~K}$ and $\mathrm{pH}=7, \Delta_{\mathrm{r}} G_{i}(i=1-5)$ can be simplified as follows:

$$
\begin{gathered}
\Delta_{\mathrm{r}} G_{1}=-1.3 \\
\Delta_{\mathrm{r}} G_{2}=E_{\text {ads }, \mathrm{HO}}+1.4 \\
\Delta_{\mathrm{r}} G_{3}=E_{\text {ads } \mathrm{H}}+2.1 \\
\Delta_{\mathrm{r}} G_{4}=2.87 E_{\mathrm{ads}, \mathrm{HO}}+8.54 \\
\Delta_{\mathrm{r}} G_{5}=3.74 E_{\text {ads }, \mathrm{HO}}+E_{\text {ads } \mathrm{H}}+16.4
\end{gathered}
$$

Substituting $\Delta_{\mathrm{r}} G_{i}(i=1-5)$ in Equation(4) with Eq. (6a-e), $x_{1}$ becomes a function of only two variables, $E_{\mathrm{ads}, \mathrm{HO}}$ and $E_{\mathrm{ads}, \mathrm{H}}$. Figure $3 \mathrm{~d}$ plots the variation in $x_{1}$ with $E_{\text {ads,HO}}$ and $E_{\text {ads }, \mathrm{H}}$. From Fig. 3d, the criterion $x_{1}>0.5$ becomes the adsorption energy criterion of Eq. (3). Using a similar method, the adsorption energy criterion at any other $\mathrm{pH}$ can be obtained.

High-throughput calculations. The high-throughput calculations of $E_{\mathrm{ads}, \mathrm{H}}$ and $E_{\mathrm{ads}, \mathrm{HO}}$ for the 2D materials were performed by the python script (Supplementary 
Table 2 Standard thermodynamic data.

\begin{tabular}{|c|c|c|c|}
\hline Item & Value & Item & Value \\
\hline$\Delta_{\mathrm{r}} \mathrm{G}_{6}^{\circ}$ & $-0.86^{a}$ & $\triangle_{\mathrm{r}} \mathrm{G}_{13}^{\circ}$ & $4.92^{b}$ \\
\hline$\Delta_{\mathrm{r}} G_{7}^{\circ}$ & $-0.86^{b}$ & $\mathrm{~S}_{\mathrm{HO}}^{\mathrm{r}}$ & $1.9 \times 10^{-3 c}$ \\
\hline$\Delta_{\mathrm{r}} G_{8}^{\prime}$ & $0.12^{b}$ & $\mathrm{~S}_{\mathrm{O}}^{\mathrm{HO}}$ & $1.7 \times 10^{-3 c}$ \\
\hline$\Delta_{\mathrm{r}} \mathrm{G}_{9}^{\circ}$ & $1.87^{b}$ & $S_{H}^{0}$ & $1.2 \times 10^{-3 c}$ \\
\hline$\Delta_{\mathrm{r}} \mathrm{G}_{10}^{\circ}$ & $2.52^{b}$ & $\triangle_{\mathrm{sol}, 2} \mathrm{G}_{\mathrm{HO} *}^{\circ}$ & $1.20^{d}$ \\
\hline$\Delta_{\mathrm{r}} \mathrm{G}_{11}^{\circ}$ & $6.68^{b}$ & $\Delta_{\mathrm{Sol}, 2} G_{\mathrm{O} *}^{\circ}$ & $1.20^{d}$ \\
\hline$\triangle_{\mathrm{r}} G_{12}^{\circ}$ & $3.59^{b}$ & $\Delta_{\mathrm{sol}, 2} G_{\mathrm{H}^{*}}^{\circ}$ & $0.81^{d}$ \\
\hline \multicolumn{4}{|c|}{$\begin{array}{l}\text { aThe data were obtained by DFT calculations using the method described in the Supplementar } \\
\text { Method section (unit: eV/particle). } \\
\text { bThe data were calculated using the data of Supplementary Table } 3 \text { (unit: eV/particle). } \\
\text { cThe data were directly taken from the chemistry handbook }{ }^{66} \text { (unit: } \mathrm{eV} / \text { particle/K). } \\
\text { dThe data were estimated from the combination of experiment and computation using the } \\
\text { method described in the Supplementary Method section (unit: } \mathrm{eV} \text { ). }\end{array}$} \\
\hline
\end{tabular}

Software 1). The calculated adsorption energies are present in Supplementary Data 3. Briefly, the script screens the 2D materials deposited in the C2DB database that satisfy the following conditions: (1) they have considerable thermodynamic stability $\left(\Delta H_{\text {hull }}<0.2 \mathrm{eV} /\right.$ atom); (2) they have considerable kinetic stability $\left(\tilde{\omega}_{\min }^{2}>10^{-5} \mathrm{eV} / \AA^{2}\right)$; (3) they contain no more than two elements; (4) they have bandgap information calculation with the HSE method; (5) they have only CBM or VBM with the orbital energy located in between $(-0.16 \mathrm{eV}, 0.94 \mathrm{eV})$. A total of 126 materials were screened out from the database. To calculate $E_{\text {ads, } \mathrm{H}}$ and $E_{\text {ads,Ho }}$ for each of these materials, we saved the unit cell structure for the material, which contains the three-unit cell vectors $(\mathbf{a}, \mathbf{b}$, and $\mathbf{c})$ and coordinates for all the atoms. We first checked the lengths of vectors $\mathbf{a}$ and $\mathbf{b}$ : if the length of $\mathbf{a}(\mathbf{b})$ is $>1.5$ times that of $\mathbf{b}(\mathbf{a})$, the length of $\mathbf{b}$ (a) will be doubled to build the new unit cell. We further checked the lengths of $\mathbf{a}$ and $\mathbf{b}$ for the cell: if the length of $\mathbf{a}$ or $\mathbf{b}$ is no larger than $5 \AA$, both $\mathbf{a}$ and $\mathbf{b}$ will be doubled. Then, all symmetrically unique adsorption sites for the cell were found to build the initial $\mathrm{H}$ and $\mathrm{HO}$ adsorption structures. All these adsorption structures were geometrically optimized using the spin-polarized DFT and crude convergence criteria, in which the total energy and force convergence were $10^{-3} \mathrm{eV}$ and $0.3 \mathrm{eV} / \AA$, respectively and the gamma point approximation was also used. The lowest-energy adsorption structure according to these preliminary calculations was recalculated with tighter convergence criteria: the total energy and force convergence was $10^{-5} \mathrm{eV}$ and $0.02 \mathrm{eV} / \AA$, respectively; a $(3 \times 3 \times 1) \mathrm{k}$-point mesh was used. For all these calculations, the unit cell parameters were frozen. The python materials genomics (Pymatgen) ${ }^{69}$ and atomic simulation environment ${ }^{70}$ packages were used to prepare the inputs of these calculations.

Experiments. The synthesis and characterization of the MIL-53(Fe)-X (X $=\mathrm{NH}_{2}$, $\mathrm{CH}_{3}, \mathrm{H}, \mathrm{OH}, \mathrm{F}, \mathrm{Cl}, \mathrm{Br}$, and $\mathrm{NO}_{2}$ ) compounds have been reported in our recent study ${ }^{42}$. The reduction potential values of the MIL-53(Fe)-X discussed in this work were also taken from the previous study ${ }^{42}$. Because the values were measured using a saturated calomel electrode (SCE) and in a buffer solution with $\mathrm{pH}=4.5$, the values were converted to those with respect to $\mathrm{HE}$ and at $\mathrm{pH}=7$ using the following equation:

$$
\varphi \mathrm{HE}(\mathrm{pH}=7)=\varphi \mathrm{SCE}(\mathrm{pH}=4.5)-0.0592 \times \Delta \mathrm{pH}+0.245
$$

where $\Delta \mathrm{pH}$ is the difference between the target $\mathrm{pH}$ and the $\mathrm{pH}$ of the measurement, namely $\Delta \mathrm{pH}=7-4.5=2.5$.

The SOD-like activities of the MIL-53(Fe)-X (X = $\mathrm{NH}_{2}, \mathrm{CH}_{3}, \mathrm{H}, \mathrm{OH}, \mathrm{F}, \mathrm{Cl}, \mathrm{Br}$, and $\mathrm{NO}_{2}$ ) MOFs were measured with the $\mathrm{O}_{2}{ }^{-}-$specific fluorescent probe hydroethidine. The probe could react with $\mathrm{O}_{2}{ }^{\bullet-}$, which was generated from the xanthine and xanthine oxidase, to give a fluorescent product ethidium peaked around $600 \mathrm{~nm}$. More $\mathrm{O}_{2}{ }^{--}$eliminated by the MOF would give a lower fluorescent intensity, demonstrating a higher SOD-like activity of MOF. In a typical experiment, $0.6 \mathrm{mM}$ xanthine, $0.05 \mathrm{U} / \mathrm{mL}$ xanthine oxidase, and $0.09 \mathrm{mg} / \mathrm{mL}$ MOFs were first added into the $0.1 \mathrm{M}$ phosphate buffer $(\mathrm{pH}=7.4)$, vortexed for a while, and then kept at $37^{\circ} \mathrm{C}$ for $30 \mathrm{~min} .0 .1 \mathrm{mg} / \mathrm{mL}$ hydroethidine probe was then added, vortexed, and kept for another $30 \mathrm{~min}$. At last, the solution was taken out and measured to assess the SOD-like activities of MOFs.

The synthesis and SOD-like activities of another MIL-47(V)-X (X $=\mathrm{H}, \mathrm{Br}$, $\mathrm{NH}_{2}$ ) MOF have been reported in our previous work ${ }^{43}$. Cyclic voltammograms measurements of the MIL-47(V)-X $\left(\mathrm{X}=\mathrm{H}, \mathrm{Br}, \mathrm{NH}_{2}\right)$ MOFs were carried out on an electrochemical workstation (CHI 660E) with a standard three-electrode system. $4 \mathrm{mg}$ MOFs and $1 \mathrm{mg}$ black were first added to the solution containing $0.48 \mathrm{~mL}$ of ethanol, $0.5 \mathrm{~mL}$ of water, and $0.02 \mathrm{~mL}$ of Nafion. After $30 \mathrm{~min}$ sonication, $0.1 \mathrm{~mL}$ of the mixture was dropped onto a carbon cloth and dried at room temperature. And then, the carbon cloth, an SCE, and a platinum sheet were used as the working electrode, the reference electrode, and the counter electrode, respectively.

\section{Data availability}

The authors declare that all other data supporting the findings of this study are available within the paper, the Supplementary Information/Source Data file.

\section{Code availability}

The tailored developed codes used in this work are available within the Supplementary Software file. Density functional theory calculations are done with the code VASP (version 5.4.4).

Received: 2 July 2021; Accepted: 5 November 2021; Published online: 25 November 2021

\section{References}

1. Sies, H. \& Jones, D. P. Reactive oxygen species (ROS) as pleiotropic physiological signalling agents. Nat. Rev. Mol. Cell Biol. 21, 363-383 (2020).

2. Karakoti, A., Singh, S., Dowding, J. M., Seal, S. \& Self, W. T. Redoxactive radical scavenging nanomaterials. Chem. Soc. Rev. 39, 4422-4432 (2010).

3. He, W. W., Wamer, W., Xia, Q. S., Yin, J. J. \& Fu, P. P. Enzyme-like activity of nanomaterials. J. Environ. Sci. Heal. C Environ. 32, 186-211 (2014).

4. Lin, Y., Ren, J. \& Qu, X. Catalytically active nanomaterials: a promising candidate for artificial enzymes. Acc. Chem. Res. 47, 1097-1105 (2014).

5. Wu, J. J. X. et al. Nanomaterials with enzyme-like characteristics (nanozymes): next-generation artificial enzymes (II). Chem. Soc. Rev. 48, 1004-1076 (2019)

6. Walkey, C. et al. Catalytic properties and biomedical applications of cerium oxide nanoparticles. Environ. Sci. Nano 2, 33-53 (2015).

7. Tsai, Y.-T., Yeh, H.-Y., Chao, C.-T. \& Chiang, C.-K. Superoxide dismutase 2 (SOD2) in vascular calcification: a focus on vascular smooth muscle cells, calcification pathogenesis, and therapeutic strategies. Oxid. Med. Cell. Longev. 2021, 6675548 (2021)

8. Celardo, I., Pedersen, J. Z., Traversa, E. \& Ghibelli, L. Pharmacological potential of cerium oxide nanoparticles. Nanoscale 3, 1411-1420 (2011).

9. Liu, G. F. et al. High catalytic activity of dendritic $\mathrm{C}_{60}$ monoadducts in metalfree superoxide dismutation. Angew. Chem. Int. Ed. 47, 3991-3994 (2008).

10. Berlin, J. M. et al. Effective drug delivery, in vitro and in vivo, by carbon-based nanovectors noncovalently loaded with unmodified Paclitaxel. ACS Nano 4, 4621-4636 (2010).

11. Jalilov, A. S. et al. Perylene diimide as a precise graphene-like superoxide dismutase mimetic. ACS Nano 11, 2024-2032 (2017).

12. Jalilov, A. S. et al. Mechanistic study of the conversion of superoxide to oxygen and hydrogen peroxide in carbon nanoparticles. ACS Appl. Mater. Interfaces. 8, 15086-15092 (2016).

13. Samuel, E. L. et al. Highly efficient conversion of superoxide to oxygen using hydrophilic carbon clusters. Proc. Natl Acad. Sci. U.SA 112, 2343-2348 (2015).

14. Ali, S. S. et al. A biologically effective fullerene $\left(C_{60}\right)$ derivative with superoxide dismutase mimetic properties. Free Radic. Biol. Med. 37, 1191-1202 (2004)

15. He, W. et al. Intrinsic catalytic activity of Au nanoparticles with respect to hydrogen peroxide decomposition and superoxide scavenging. Biomaterials 34, 765-773 (2013)

16. Ge, C. C. et al. Facet energy versus enzyme-like activities: the unexpected protection of palladium nanocrystals against oxidative damage. ACS Nano 10 , 10436-10445 (2016)

17. Jawaid, P. et al. Helium-based cold atmospheric plasma-induced reactive oxygen species-mediated apoptotic pathway attenuated by platinum nanoparticles. J. Cell. Mol. Med. 20, 1737-1748 (2016).

18. Ragg, R. et al. Intrinsic superoxide dismutase activity of $\mathrm{MnO}$ nanoparticles enhances the magnetic resonance imaging contrast. J. Mater. Chem. B 4, 7423-7428 (2016).

19. Li, W. et al. Manganese dioxide nanozymes as responsive cytoprotective shells for individual living cell encapsulation. Angew. Chem. Int. Ed. 56, 13661-13665 (2017)

20. Huang, Y. Y. et al. Self-assembly of multi-nanozymes to mimic an intracellular antioxidant defense system. Angew. Chem. Int. Ed. 55, 6646-6650 (2016).

21. Namrata, S., Geethika, M., Eswarappa, S. M. \& Govindasamy, M. Manganesebased nanozymes: multienzyme redox activity and effect on the nitric oxide produced by endothelial nitric oxide synthase. Chem. Eur. J. 24, 8393-8403 (2018).

22. Singh, N., Savanur, M. A., Srivastava, S., D’Silva, P. \& Mugesh, G. A redox modulatory $\mathrm{Mn}_{3} \mathrm{O}_{4}$ nanozyme with multi-enzyme activity provides efficient cytoprotection to human cells in a parkinson's disease model. Angew. Chem. Int. Ed. 56, 14267-14271 (2017).

23. Yao, J. et al. ROS scavenging $\mathrm{Mn}_{3} \mathrm{O}_{4}$ nanozymes for in vivo antiinflammation. Chem. Sci. 9, 2927-2933 (2018). 
24. Dong, J. L. et al. $\mathrm{Co}_{3} \mathrm{O}_{4}$ nanoparticles with multi-enzyme activities and their application in immunohistochemical assay. ACS Appl. Mater. Inter. 6, 1959-1970 (2014).

25. Mu, J., Zhao, X., Li, J., Yang, E. C. \& Zhao, X. J. Novel hierarchical NiO nanoflowers exhibiting intrinsic superoxide dismutase-like activity. J. Mater Chem. B 4, 5217-5221 (2016).

26. Korsvik, C., Patil, S., Seal, S., Self, W. T. Superoxide dismutase mimetic properties exhibited by vacancy engineered ceria nanoparticles. Chem. Commun., 1056-1058 (2007).

27. Chen, T. et al. Nanozymatic antioxidant system based on $\mathrm{MoS}_{2}$ nanosheets. ACS Appl. Mater. Inter. 10, 12453-12462 (2018).

28. Feng, W. et al. 2D vanadium carbide MXenzyme to alleviate ROS-mediated inflammatory and neurodegenerative diseases. Nat. Commun. 12, 2203 (2021).

29. Ren, X. et al. Highly catalytic niobium carbide (MXene) promotes hematopoietic recovery after radiation by free radical scavenging. ACS Nano 13, 6438-6454 (2019).

30. Zhou, Y., Liu, B., Yang, R. \& Liu, J. Filling in the gaps between nanozymes and enzymes: challenges and opportunities. Bioconjugate Chem. 28, 2903-2909 (2017).

31. Osuna, S., Swart, M. \& Sola, M. On the mechanism of action of fullerene derivatives in superoxide dismutation. Chem. Eur. J. 16, 3207-3214 (2010).

32. Wang, Z. Z., Shen, X. M., Gao, X. F. \& Zhao, Y. L. Simultaneous enzyme mimicking and chemical reduction mechanisms for nanoceria as a bioantioxidant: a catalytic model bridging computations and experiments for nanozymes. Nanoscale 11, 13289-13299 (2019).

33. Shen, X. M. et al. Mechanisms of oxidase and superoxide dismutation-like activities of gold, silver, platinum, and palladium, and their alloys: a general way to the activation of molecular oxygen. J. Am. Chem. Soc. 137, 15882-15891 (2015).

34. Sheng, Y. et al. Superoxide dismutases and superoxide reductases. Chem. Rev. 114, 3854-3918 (2014).

35. Huang, C., Wang, Z.-Q. \& Gong, X.-Q. Activity and selectivity of propane oxidative dehydrogenation over $\mathrm{VO}_{3} / \mathrm{CeO}_{2}(111)$ catalysts: a density functional theory study. Chin. J. Catal. 39, 1520-1526 (2018).

36. Wu, X.-P. \& Gong, X.-Q. Unique electronic and structural effects in vanadia/ ceria-catalyzed reactions. J. Am. Chem. Soc. 137, 13228-13231 (2015).

37. Zhou, W. et al. Intrinsic structural defects in monolayer molybdenum disulfide. Nano Lett. 13, 2615-2622 (2013).

38. Esch, F. et al. Electron localization determines defect formation on ceria substrates. Science 309, 752-755 (2005)

39. Han, Z. K., Yang, Y. Z., Zhu, B. E., Ganduglia-Pirovano, M. V. \& Gao, Y. Unraveling the oxygen vacancy structures at the reduced $\mathrm{CeO}_{2}(111)$ surface. Phys. Rev. Mater. 2, 035802 (2018).

40. Yang, Y. et al. Redox enzyme-mimicking activities of $\mathrm{CeO}_{2}$ nanostructures: Intrinsic influence of exposed facets. Sci. Rep. 6, 35344 (2016).

41. Capdevila-Cortada, M. \& Lopez, N. Entropic contributions enhance polarity compensation for $\mathrm{CeO}_{2}(100)$ surfaces. Nat. Mater. 16, 328-334 (2017).

42. $\mathrm{Wu}$, J. et al. Hammett relationship in oxidase-mimicking metal-organic frameworks revealed through a protein-engineering-inspired strategy. Adv. Mater. 33, e2005024 (2021).

43. $\mathrm{Wu}, \mathrm{J}$. et al. Ligand-Dependent activity engineering of glutathione peroxidasemimicking MIL-47(V) metal-organic framework nanozyme for therapy. Angew. Chem. Int. Ed. 60, 1227-1234 (2021)

44. Haastrup, S. et al. The computational 2D materials database: High-throughput modeling and discovery of atomically thin crystals. 2D Mater. 5, 042002 (2018).

45. Zhao, D. et al. Synthesis of large-scale few-layer $\mathrm{PtS}_{2}$ films by chemical vapor deposition. AIP Adv. 9, 025225 (2019).

46. Fox, J. J. et al. Chemical vapor transport synthesis, characterization and compositional tuning of $\mathrm{ZrS}_{\mathrm{x}} \mathrm{Se}_{2-\mathrm{x}}$ for optoelectronic applications. J. Cryst. Growth 542, 125609 (2020).

47. Shao, G. et al. Shape-engineered synthesis of atomically thin $1 \mathrm{~T}-\mathrm{SnS}_{2}$ catalyzed by potassium halides. ACS Nano 13, 8265-8274 (2019).

48. Fu, L. et al. Van der waals epitaxial growth of atomic layered $\mathrm{HfS}_{2}$ crystals for ultrasensitive near-infrared phototransistors. Adv. Mater. 29, 1700439 (2017).

49. Zhou, L. et al. Large-area synthesis of high-quality uniform few-layer $\mathrm{MoTe}_{2}$. J. Am. Chem. Soc. 137, 11892-11895 (2015).

50. Tonndorf, P. et al. Photoluminescence emission and Raman response of monolayer $\mathrm{MoS}_{2}, \mathrm{MoSe}_{2}$, and WSe 2 . Opt. Express 21, 4908-4916 (2013).

51. Li, S. et al. Synthesis of semiconducting $2 \mathrm{H}$-phase $\mathrm{WTe}_{2}$ nanosheets with large positive magnetoresistance. Inorg. Chem. 59, 11935-11939 (2020).

52. Karthick, K. et al. Enhancing hydrogen evolution reaction activities of $2 \mathrm{H}$ phase $\mathrm{VS}_{2}$ layers with palladium nanoparticles. Inorg. Chem. 59, 10197-10207 (2020).

53. M. Adachi, K. Nakagawa, K. Sago, Y. Murata, Y. Nishikawa, Formation of $\mathrm{GeO}_{2}$ nanosheets using water thin layers in lamellar phase as a confined reaction field-in situ measurement of SAXS by synchrotron radiation. Chem. Commun. 2381-2383 (2005).
54. Bianco, E. et al. Stability and exfoliation of germanane: A germanium graphane analogue. ACS Nano 7, 4414-4421 (2013).

55. Zhang, P. et al. Sonication-assisted liquid-phase exfoliated a-GeTe: a twodimensional material with high $\mathrm{Fe}^{3+}$ sensitivity. Nanoscale 10, 15989-15997 (2018).

56. Zhao, X. et al. Van der Waals epitaxy of ultrathin crystalline PbTe nanosheets with high near-infrared photoelectric response. Nano Res. 14, 1955-1960 (2021).

57. Sines, I. T. et al. Engineering porosity into single-crystal colloidal nanosheets using epitaxial nucleation and chalcogenide anion exchange reactions: The conversion of SnSe to SnTe. Chem. Mater. 24, 3088-3093 (2012).

58. Blochl, P. E. Projector augmented-wave method. Phys. Rev. B 50, 17953-17979 (1994).

59. Kresse, G. \& Furthmüller, J. Efficiency of ab-initio total energy calculations for metals and semiconductors using a plane-wave basis set. Comp. Mater. Sci. 6, 15-50 (1996)

60. Perdew, J. P., Burke, K. \& Ernzerhof, M. Generalized gradient approximation made simple. Phys. Rev. Lett. 77, 3865-3868 (1996).

61. Anisimov, V. I., Zaanen, J. \& Andersen, O. K. Band theory and mott insulators-hubbard-U instead of stoner-I. Phys. Rev. B 44, 943-954 (1991).

62. Dudarev, S. L., Botton, G. A., Savrasov, S. Y., Humphreys, C. J. \& Sutton, A. P. Electron-energy-loss spectra and the structural stability of nickel oxide: An LSDA+U study. Phys. Rev. B 57, 1505-1509 (1998).

63. Mathew, K., Sundararaman, R., Letchworth-Weaver, K., Arias, T. A. \& Hennig, R. G. Implicit solvation model for density-functional study of nanocrystal surfaces and reaction pathways. J. Chem. Phys. 140, 084106 (2014).

64. Mathew, K., Kolluru, V. S. C., Mula, S., Steinmann, S. N. \& Hennig, R. G. Implicit self-consistent electrolyte model in plane-wave density-functional theory. J. Chem. Phys. 151, 234101 (2019).

65. Henkelman, G., Uberuaga, B. P. \& Jónsson, H. A climbing image nudged elastic band method for finding saddle points and minimum energy paths. $J$. Chem. Phys. 113, 9901-9904 (2000).

66. Dean, J. A., Dean, J. A. Ed. Lange's Handbook of Chemistry (McGRAW-HILL, INC., New York, 1998).

67. Abild-Pedersen, F. et al. Scaling properties of adsorption energies for hydrogen-containing molecules on transition-metal surfaces. Phys. Rev. Lett. 99, 016105 (2007).

68. Liang, Z. et al. Evaluating the catalytic activity of transition metal dimers for the oxygen reduction reaction. J. Colloid Interf. Sci. 568, 54-62 (2020).

69. Montoya, J. H. \& Persson, K. A. A high-throughput framework for determining adsorption energies on solid surfaces. NPJ Comput. Mater. 3, 1-14 (2017).

70. Hjorth Larsen, A. et al. The atomic simulation environment-a Python library for working with atoms. J. Phys.: Condens. Matter 29, 273002 (2017).

\section{Acknowledgements}

This work was supported by the National Natural Science Foundation of China (NSFC) (Project nos. 21773095). Z.W., J.W., and X.S. were partially supported by the China Postdoctoral Science Foundation (2019M660581) and NSFC (22007041), respectively.

\section{Author contributions}

X.G. conceived the project and performed the high-throughput calculations. Z.W., J.J.Z., and X.S. perform the other DFT calculations. J.W. and L.Y. performed the experiments H.W. and Y.Z. advised on the experimental data. Z.W. drafted the initial manuscript, then X.G. prepared the final manuscript with approval from all the authors.

\section{Competing interests}

The authors declare no competing interests.

\section{Additional information}

Supplementary information The online version contains supplementary material available at https://doi.org/10.1038/s41467-021-27194-8.

Correspondence and requests for materials should be addressed to Xingfa Gao.

Peer review information Nature Communications thanks the anonymous reviewer(s) for their contribution to the peer review of this work.

Reprints and permission information is available at http://www.nature.com/reprints

Publisher's note Springer Nature remains neutral with regard to jurisdictional claims in published maps and institutional affiliations. 
(c) (i) Open Access This article is licensed under a Creative Commons Attribution 4.0 International License, which permits use, sharing, adaptation, distribution and reproduction in any medium or format, as long as you give appropriate credit to the original author(s) and the source, provide a link to the Creative Commons license, and indicate if changes were made. The images or other third party material in this article are included in the article's Creative Commons license, unless indicated otherwise in a credit line to the material. If material is not included in the article's Creative Commons license and your intended use is not permitted by statutory regulation or exceeds the permitted use, you will need to obtain permission directly from the copyright holder. To view a copy of this license, visit http://creativecommons.org/ licenses/by/4.0/.

(C) The Author(s) 2021 